inconventional cardiovascular risk factors. Exclusion criteria were smoking, diabetes mellitus, symptomatic $\mathrm{AH}$, cardiovascular diseases (except $\mathrm{AH}$ ). DMAS was measured by using the BPlab with technology VASOTENSE (Russian).An index of arterial stiffness (ASI), a daily index of arterial stiffness (AASI), an aortic pulse wave velocity (PWVao), augmentation index (AIX) were measured. All indexes were estimated at day and night hours.

Statistics was performed with STATISTICA 7.0 (StatSoft, USA).

Results: Hypertensive RA patients and AH patients without RA had comparable DMAS parameters (ASI, PWVao, Alx). The AASI index was higher in RA patients without $A H$ versus controls $(0.48 \pm 0.2$ and $0.29 \pm 0.17$, respectively, $p=0.00001)$ and the AASI index was higher in hypertensive RA patients versus AH patients $(0.5 \pm 0.2$ and $0.38 \pm 0.15$, respectively, $p=0.01)$. AASI $>0.07$ revealed at RA patients more often than in controls: at $13.15 \%$ of hypertensive RA patients and at $16.6 \%$ of RA patients without $A H$, respectively, $p<0.05$. The increase of PWVao observed at RA patients frequently than in controls $(p<0.05)$.

Daily index ASI100 was higher in RA patients without $\mathrm{AH}$ than in healthy controls $(121[109.5 ; 139] \mathrm{mmHg}$ vs. $107[103 ; 115] \mathrm{mmHg}, \mathrm{p}=0.014)$.

The increased of $\mathrm{Al} \times 75$ was registered in $25 \%$ of $\mathrm{RA}$ patients without $\mathrm{AH}$ and in $9.09 \%$ of controls $(p=0.08)$. PWVao and average Aix75 correlates with ESR ( $r$ $=0.38$ and $r=0.36$, respectively, $p<0.05)$ in RA patients with AH; AASI correlates with level $\mathrm{C}$-reactive protein $(\mathrm{r}=0.36, \mathrm{p}<0.05)$.

ASI and AASI in RA patients with AH correlates with age (Spearmen's $r=0.41$ and $r=0.36$, respectively, $p<0.05)$, systolic blood pressure $(r=0.76$ and $r=0.65$, respectively, $p<0.05)$; pulse blood pressure $(r=0.77$ and $r=0.43$, respectively, $p<0,05)$.

Conclusions: Arterial stiffness, according to daily monitoring, in RA patients is higher than in hypertensive patients without RA and healthy controls. Arterial stiffness in patients with RA and $A H$ is higher than in patients with RA without $A H$ or AH without RA. Age, systolic blood pressure, pulse blood pressure, high levels of ESR and C-reactive protein associated with increased arterial stiffness in RA patients.

Disclosure of Interest: None declared

DOI: 10.1136/annrheumdis-2017-eular.5683

\section{SAT0135 CARDIOVASCULAR RISK IN RHEUMATOID ARTHRITIS PATIENTS FROM SOUTHERN BRAZIL AND ITS ASSOCIATION WITH SERUM LEVELS AND GENOTYPIC VARIATION OF MANNOSE BINDING LECTIN}

B. Stadler ${ }^{1}$, T.A.F.G. Dos Santos ${ }^{1}$, T. Skare ${ }^{1}$, R. Nisihara ${ }^{1,2}$, R. Petisco ${ }^{3}$, I. Goeldner ${ }^{2}$, S. Utiyama ${ }^{4}$, I.J.T. Messias-Reason ${ }^{2} .{ }^{1}$ Rheumatology Unit, Hospital Universitário Evangelico de Curitiba; ${ }^{2}$ Department of Medical Pathology, Federal University of Paraná; ${ }^{3}$ Evangelic School of Medicine; ${ }^{4}$ Department of Clinical Analysis, Federal University of Paraná, Curitiba, Brazil

Background: The binding lectin mannose (MBL) is a serum protein of collectin family that appears to be involved in the inflammatory process and in the genesis of atherosclerotic disease.

Objectives: To study the association of serum levels of MBL and its genotypic variation with carotid arteries intimal thickness (IMT) in rheumatoid arthritis (RA) patients from Southern Brazil.

Methods: Serum level, MBL genotyping and IMT were studied in 90 RA patients along with their demographic, clinical and laboratory profile. MBL levels were measured in 90 healthy controls.

Results: There was significant difference between mean serum levels of MBL in patients with RA and controls ( $528 \mathrm{ng} / \mathrm{mL}$ vs $937.5 \mathrm{ng} / \mathrm{mL}, p=0.05$, respectively). The median IMT in RA patients was $0.59 \mathrm{~mm}(0.51$ to $0.85 \mathrm{~mm})$. There was no correlation between levels of MBL with disease activity measured by DAS-28 (disease activity score-28), erythrocyte sedimentation rate (ESR), autoantibodies presence or IMT ( $p=N S)$. A negative correlation was found between MBL levels with CRP levels $(\mathrm{p}=0.02)$. The mutation vat codon 54 (variant $\mathrm{B})$ and HYPA haplotype were the most frequent $(67.5 \%$ and $31.7 \%$, respectively) in the RA sample. Dominant genotypes $(\mathrm{A} / \mathrm{A})$ are associated with lower IMT when compared with heterozygotes $(\mathrm{A} / \mathrm{O} ; \mathrm{p}=0.04)$ and homozygous recessive $(\mathrm{O} / \mathrm{O} ; \mathrm{p}=0.05)$. Also dominant genotypes had lower CRP when compared with heterozygous $(p=0.04)$ or with recessive genotypes $(p=0.05)$.
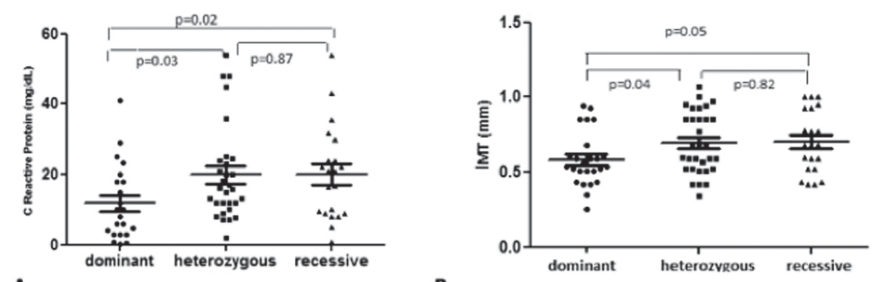

A B THICKNESS (IMT)

Conclusions: RA patients had lower MBL levels than controls. MBL serum levels are negatively associated with CRP; low producers of MBL had increased thickness of the IMT than high producers.
References:

[1] Scarno A, Perrotta FM, Cardini F, Carboni A, Annibali G, Lubrano E, et al. Beyond the joint: Subclinical atherosclerosis in rheumatoid arthritis. World J Orthop [Internet]. 2014;5(3):328-35. Available from: http://www.wjgnet. com/2218-5836/full/v5/.

[2] Ip WK, Lau YL, Chan SY, Mok CC, Chan D, Tong KK, et al. Mannosebinding lectin and rheumatoid arthritis in southern Chinese. Arthritis Rheum. 2000;43(8):1679-87.

[3] J Maury CP, Aittoniemi J, Tiitinen S, Laiho K, Kaarela K, Hurme M, et al. Variant mannose-binding lectin 2 genotype is a risk factor for reactive systemic amyloidosis in rheumatoid arthritis. Jounal Intern Med. 2007;262:466-9.

[4] Graudal NA, Homann C, Madsen HO, Svejgaard A, Jurik AG, Graudal HK, et al. Mannan Binding Lectin in Rheumatoid Arthritis. A Longitudinal Study. J Rheumatol. 1998;25(4):629-35.

[5] Carvalho EG, Utiyama SRR, Kotze LMS, Reason ITM. Lectina ligante de manose (MBL): características biológicas e associação com doenças. Res bras alerg imunopatol. 2007;30(5):187-93.

Disclosure of Interest: None declared

DOI: 10.1136/annrheumdis-2017-eular.6998

\section{SAT0136 ASSOCIATION OF GENOTYPES FOR BCL1 POLYMORPHISM IN THE GLUCOCORTICOID RECEPTOR GENE WITH ISCHEMIC HEART DISEASE IN PATIENTS WITH RHEUMATOID ARTHRITIS}

V.S.S.U. Kmyta, O. Savchenko, L. Prystupa. Internal Medicine Department, 4682, Sumy, Ukraine

Objectives: The objective is to study association of genotypes for Bcl1 polymorphism in the glucocorticoid receptor (GR) gene with ischemic heart disease (IHD) in patients with rheumatoid arthritis (RA).

Methods: 161 subjects with rheumatoid arthritis aged 40 years and older were examined by means of instrumental, clinical and laboratory examinations. Rheumatoid arthritis was diagnosed according to ACR/EULAR Classification Criteria (2010). The IHD diagnosis was verified by means of AHA/ACC guidelines (2012). BCL1 polymorphism in exon 2 was identified using polymerase chain reaction with subsequent analysis of restriction fragment length polymorphism by Fleury I. et al. (venous blood was used as the material for the study). Statistical analysis was performed using SPSS-17 program.

Results: It was revealed that $76(47.2 \%)$ patients had isolated RA (group I), while $85(52.8 \%)$ individuals had RA with concomitant IHD (group II). In group I, there were $29(38.2 \%)$ patients with C/C genotype, $39(51.3 \%)$ - with C/G genotype, and $8(10.5 \%)$ - with $\mathrm{G} / \mathrm{G}$ genotype. The distribution in group I was as following: 16 were homozygous for the $C$ allele $(18.8 \%), 40$ were heterozygous $(47.1 \%)$ and 29 were homozygous for the G allele $(34.1 \%)\left(x^{2}=15.23 ; p=0.02\right)$. It was established that the risk of ischemic heart disease was 6.57 times higher in homozygotes for the $\mathrm{G}$ allele (OR=6.57; $95 \% \mathrm{Cl}=2.44-17.73 ; \mathrm{p}=0.001)$ as compared with homozygotes for the $\mathrm{C}$ allele.

Conclusions: It was established that $\mathrm{G} / \mathrm{G}$ genotype prevailed in RA patients with ischemic heart disease, while $\mathrm{C} / \mathrm{C}$ genotype prevailed in patients with isolated $\mathrm{RA}$. The risk of IHD development in patients with RA was associated with $\mathrm{G} / \mathrm{G}$ genotype for Bcl1 polymorphism in the GR gene.

Disclosure of Interest: None declared

DOI: 10.1136/annrheumdis-2017-eular.3998

\section{SAT0137 BONE MINERAL DENSITY MEASUREMENT INTERVALS FOR SEROPOSITIVE RHEUMATOID ARTHRITIS PATIENTS NOT TREATED FOR OSTEOPOROSIS}

W. Park, K.-H. Jung, S.-R. Kwon, M.-J. Lim, S.-G. Park, M.-J. Jo. In-Ha University Hospital, Incheon, Korea, Republic Of

Background: Osteoporosis occurs more frequently in rheumatoid arthritis (RA) patients than in healthy individuals. However the appropriate interval for the bone mineral density (BMD) measurement in RA patients is not well established.

Objectives: This study investigated the effective BMD measurement interval and the risk factors associated with the development of osteoporosis for RA patients. Methods: A retrospective study was performed on 511 RA patients aged more than 40 years old who had undergone BMD (DXA, GE LUNAR PRODIGY ADVANCE) testing more than once and who had normal BMD or osteopenia at the baseline BMD test and no history of any fracture of the spine or femur. The subjects were categorized into four subgroups: normal BMD (T-score $>-1)$, mild $(-1 \geq$ T-score $>-1.5)$, moderate $(-1.5 \geq T$-score $>-2)$, and advanced $(-2 \geq T$-score $>-2.5)$ osteopenia. The BMD testing interval was defined as the estimated time for $10 \%$ of the RA patients to make the transition into osteoporosis without osteoporotic fracture or the administration of any osteoporosis drug.

Results: The observation period was 2,214 patient-years, with an average of 4.3 years. The estimated BMD testing interval was more than 10 years for normal, 4.3 years for mild, 2.5 years for moderate, and 1.5 years for advanced osteopenia in each of the RA patient groups.

Conclusions: Our study indicated that in normal or osteopenic RA groups, a baseline BMD T-score is the most important factor in estimating the interval in which osteoporosis is predicted to occur. In addition, we recommend that the BMD measuring interval should be greater than 10 years in normal BMD RA 
Table 1. Interval between baseline BMD testing and the development of osteoporosis

\begin{tabular}{|c|c|c|c|c|}
\hline \multirow[t]{2}{*}{ Baseline BMD } & \multicolumn{2}{|c|}{$\begin{array}{c}\text { Mean interval to develop } \\
\text { osteoporosis } \\
\text { (year) }\end{array}$} & \multicolumn{2}{|c|}{$\begin{array}{l}\text { Mean interval to develop } \\
\text { osteoporosis in } 10 \% \text { of } \\
\text { each group (year) }\end{array}$} \\
\hline & Lumbar spine & Femur neck & Lumbar spine & Femur neck \\
\hline$\overline{\text { Norm }}$ & $9.4(9.29-9.49)^{a}$ & $9.4(9.25-9.53)^{a}$ & $>10$ & $>10$ \\
\hline Mild osteopenia & $9.2(8.58-9.71)^{\mathrm{a}}$ & $9.1(8.94-9.22)^{a}$ & 4.3 & $>10$ \\
\hline Moderate osteopenia & $7.9(6.94-8.76)^{\mathrm{a}}$ & $9.4(8.93-9.87)^{\mathrm{a}}$ & 2.5 & 7.5 \\
\hline Advanced osteopenia & $5.4(4.61-6.21)^{\mathrm{a}}$ & $8.6(7.68-9.50)^{a}$ & 1.5 & 2.2 \\
\hline
\end{tabular}

BMD, bone mineral density. ${ }^{~}$ Mean $(95 \%$ confidence interval).

patients, 4 years in mild, 2 years in moderate, and 1 year in advanced osteopenic RA patients on the basis of L-spine BMD.

Disclosure of Interest: None declared

DOI: 10.1136/annrheumdis-2017-eular.4638

\section{SAT0138 OPTIMIZING TARGETED THERAPY: CAN PROMS FILL THE GAP BETWEEN PATIENTS- AND PHYSICIAN- PERCEIVED REMISSION IN RHEUMATOID ARTHRITIS}

Y. El Miedany ${ }^{1}$, M. El Gaafary ${ }^{2}$, N. El Arousi ${ }^{3}$, S.S. Youssef ${ }^{3}$, D. Palmer ${ }^{4}$. ${ }^{1}$ Rheumatology, Darent Valley Hospital, Dartford, United Kingdom; ${ }^{2}$ Community and Public health; ${ }^{3}$ Rheumatology and Rehabilitation, Ain Shams University, Cairo, Egypt; ${ }^{4}$ Rheumatology, North Middlesex University Hospital, London, United Kingdom

Objectives: 1. To compare the patient perspective on remission in RA in comparison to the rheumatologist perceived remission perspectives.

2. To determine the value of Patient Reported outcomes in identifying specific symptoms and aspects of disease able to define remission in RA from the patient perspective.

Methods: RA patients diagnosed according to ACR/EULAR criteria were treated according to treat-to-target regime with regular disease activity monitoring (every 1-3months). Remission was measured in two ways: 1) patient perceived remission using the question "Would you say that, at this moment, your disease activity is as good as gone? (yes/no)"; and 2) Physician perceived remission was defined as a physician global assessment $\leq 1$ on a $0-10$ VAS, phrased: "How active do you think the rheumatoid arthritis of your patient is today?" The study included 188 RA patients (76 males, 112 females; mean age $52.4 \pm 11$ years) and 87 rheumatologists ( 30 males, 57 females; mean age $48.7 \pm 11.7$ years). All participants were asked to complete a questionnaire which was composed of all domains identified in relation to the disease remission. $10 \mathrm{~cm}$ visual analogue scale (scored 0-10) was used to illustrate the importance of each factor in an individual opinion. The list included joint pain, functional ability, quality of life, absence of morning stiffness, absence of fatigue, normal laboratory tests, no comorbidity risk, radiologic remission, Disease Activity score and ability to work. In addition, patients were asked to complete a copy of the PROMs [1]. One-way analysis of variance was used for the comparison of independent variables. Spearman correlation coefficient was used to assess the correlation between variables.

Results: There were no significant differences in questionnaire answers in relation to patients' demographics and present disease activity. Regarding the patient perceived remission, the top 4 were: pain $(76 \%)$, functional ability $(71 \%)$, quality of life $(69 \%)$ and fatigue $(43 \%)$. Regarding the physician perceived remission, the following factors were rated more relevant by rheumatologists than the patients $(p<0.001)$ : low disease activity score $(88 \%)$, radiologic remission and progression of erosions $(76 \%)$, lab measures (ESR/CRP) $(57 \%)$ followed by difficulties in performing paid work $(49 \%)$.

Functional ability was scored significantly higher in patients $>65$ as compared with patients $<65$ years of age ( 9.6 vs 8.1 on VAS, $p=0.03$ ). In contrast the patient's cohort $<65$ years of age, rated quality of life at a higher level (9.7) than those below 65 (8.4). Functional ability was scored higher in patients with longer-standing disease as compared to patients with shorter disease duration $(p<0.05)$. PROMs enabled the patient and the treating physician identify the aspects of relevance necessary for optimal clinical management.

Conclusions: Different factors are important for rheumatologists and RA patients regarding disease remission. Treatment satisfaction is determined not only by disease activity indices but also by other patient-oriented factors. PROMs could optimise targeted therapy as it can play a significant role in identifying disease activity parameters relevant to both the treating rheumatologist as well as the patient.

References:

[1] El Miedany et al. Clin Exp Rheumatol 2010; 28(5):734-44.

Disclosure of Interest: None declared

DOI: 10.1136/annrheumdis-2017-eular.4491

\section{SAT0139 ASSESSING ENTHESITIS BY ULTRASONOGRAPHY IN PATIENTS WITH SERONEGATIVE RHEUMATOID ARTHRITIS}

Z. Erturk ${ }^{1}$, T. Özsoy ${ }^{2}$, I. Yağcı ${ }^{2}$, Y. Yalçınkaya ${ }^{1}$, Ü. Gazel ${ }^{1}$, P. Atagündüz ${ }^{1}$, H. Direskeneli ${ }^{1}$, N. İnanç ${ }^{1} .{ }^{1}$ Rheumatology; ${ }^{2}$ Physical Therapy and Rehabilitation, Marmara University, Istanbul, Turkey

Background: In patients with seronegative rheumatoid arthritis (RA) there is a difficulty to make the differential diagnosis with the spondyloarthropathies.

Objectives: To assess the presence of enthesitis in patients with seronegative rheumatoid arthritis in comparison with the healthy controls, patients with seropositive rheumatoid arthritis and ankylosing spondylitis.

Methods: In this cross-sectional study, seronegative and seropositive rheumatoid arthritis patients, who fulfilled the 2010 ACR/EULAR criteria, patients with ankylosing spondylitis and healthy controls have been assessed by grey scale and power doppler ultrasonography for the presence of enthesopathy at the achilles, plantar fascia, proximal patella, distal patella, quadriceps, tibialis anterior, triceps, common flexor and extensor tendons. Clinical assessment of the patient groups included demographic findings, health assessment questionnaire and disease activity score.

Results: In our study, we recruited age and sex matched 27 seronegative RA, 17 healthy controls, 20 seropositive RA and 12 ankylosing spondylitis patients. We evaluated and analysed both right and left sides of the enthesis regions separately which have been indicated in the methods section. The mean DAS28, mean ESR and mean CRP of the patients with seronegative RA were $3.6 \pm 1.28$, $32.2 \pm 21.2$ and $12.37 \pm 27.77$ respectively (Table 1 ).

Median of Madrid sonographic enthesitis index (MASEI) was 5 in patients with seronegative RA. 4 patients have severe scores. There were significant differences between seronegative RA and healthy controls $(3, p=0.014)$ but no differences has been observed between seronegative RA with seropositive RA (6) and anklosing spondylitis (7) in MASEI scores.

In comparison, hypoechogenicity of quadriceps tendon (16 $(29.6 \%)$ vs $1(2.5 \%)$, $p=0.001)$, bone erosion at the quadriceps tendon attachment (9 $(16.6 \%)$ vs 0 , $\mathrm{p}=0.007$ ), hypoechogenicity of triseps $(13(24 \%)$ vs $7(17.5 \%), p=0.049)$ have been observed more frequently in patients with seronegative RA than seropositive RA. Significantly higher number of patients with bone erosion at the distal patella $(10(41.6 \%)$ v $3(5.5 \%), p=<0.001)$, enthesophyte of achilles tendon $(7(29.1 \%)$ vs $2(3.7 \%), p=0.001)$ have been detected enthesophyte of proximal patella (7 $(29.1 \%)$ vs $0, p \leq 0.001)$ in patients with ankylosing spondylitis than seronegative RA.

Table 1

\begin{tabular}{lcccc}
\hline & $\begin{array}{c}\text { Seronegative } \\
\text { RA }\end{array}$ & $\begin{array}{c}\text { Healthy } \\
\text { controls }\end{array}$ & $\begin{array}{c}\text { Seropositive } \\
\text { RA }\end{array}$ & $\begin{array}{c}\text { Ankylosing } \\
\text { spondylitis }\end{array}$ \\
\hline Age, years & $51,85 \pm 11,49$ & $44,42 \pm 7,6$ & $52,05 \pm 11,26$ & $41,75 \pm 5,1$ \\
Women, $n$ (\%) & $48(88,9)$ & $34(100)$ & $36(90)$ & $20(83)$ \\
RA duration, year & $9,8 \pm 6,75$ & & $11,25 \pm 9,1$ & \\
RF titre (median) & $10,77 \pm 3,21$ & & $345,88 \pm 405,32$ & $12,1 \pm 3,23$ \\
Anti-CCP titre, median & $3,99 \pm 4,13$ & & $326,81 \pm 286,2$ & $4,32 \pm 3,7$ \\
DAS28, median & $3,6 \pm 1,28$ & & $3,73 \pm 1,45$ & \\
ESR, median & $32,2 \pm 21,2$ & $23,3 \pm 11,8$ & $41,63 \pm 28,07$ & $19,83 \pm 9,38$ \\
CRP, median & $12,37 \pm 27,77$ & $3,14 \pm 3,87$ & $14,34 \pm 19,97$ & $6,61 \pm 5,6$ \\
\hline
\end{tabular}

Conclusions: We observed that enthesis involvement was not seldom in patients with seronegative RA. Furthermore there were also similar frequency of entesis involvement in seropositive patients with RA. The value of enthesis sites evaluationfor the differential diagnosis of patients with seronegative RA should be further investigated and the assessment of enthesis sites in seronegative and seropositive RA patients can be important to detect active and chronic changes at the enthesis region.

Disclosure of Interest: None declared

DOI: 10.1136/annrheumdis-2017-eular.4457

\section{SATURDAY, 17 JUNE 2017 \\ Rheumatoid arthritis - anti-TNF therapy}

\section{SAT0140 EFFECT OF OBESITY IN RESPONSE TO BIOLOGICS IN RHEUMATOID ARTHRITIS}

A. Khan ${ }^{1}$, S. Sukumaran ${ }^{2}$, M. Kanitkar ${ }^{1}$, A.-S. Zafar ${ }^{2}$, S. Shah ${ }^{2}$, S. Adnan ${ }^{2}$. ${ }^{1}$ Department of Rheumatology, Queen Elizabeth Queen Mother Hospital, Margate; ${ }^{2}$ Department of Rheumatology, William Harvey Hospital, Ashford, United Kingdom

Background: Obesity epidemic has impacted practically every area of health including care of patients with RA. Adipose tissue is an active organ that produces pro-inflammatory molecules. A significant treatment challenge remains is the standard dose of RA medications may not attain same concentrations at sites of inflammation in obese vs non-obese patients thus making them less effective.

Objectives: The study aim was to determine whether obesity represents a risk factor for a poor remission in RA requiring biologic therapies. Obesity may be associated with more severe and refractory inflammation through increased levels of inflammatory adipocytokines leptin, resistin or visfatin or decreased levels of the anti-inflammatory adipocytokine adiponectin. We retrospectively analysed 178 patients diagnosed with RA at East Kent University Hospitals.

Methods: Data analysed for age, sex, disease duration, prior DMARD, positivity $\mathrm{RF}$ and anti-CCP antibodies and response to biologics DAS28 score pre-treatment and at 6 months were analysed.Main aim was to analyse any difference between obese and non-obese patients in terms of their response to treatment. Obese patients were defined with a BMI of 30 or above.

Results: See Table 1. 